\title{
TECNOLOGIAS, MÚLTIPLAS LINGUAGENS E PRÁTICAS PEDAGÓGICAS NA FORMAÇÃO SUPERIOR A DISTÂNCIA
}

\author{
TECHNOLOGIES, MULTIPLE LANGUAGES AND PEDAGOGICAL PRACTICES IN \\ HIGHER DISTANCE EDUCATION
}
TECNOLOGÍAS, MÚLTIPLES LENGUAJES Y PRÁCTICAS PEDAGÓGICAS EN EDUCACIÓN SUPERIOR A DISTANCIA

\author{
Mônica Cristina Garbin ${ }^{1}$; Édison Trombeta de Oliveira ${ }^{2}$
}

\begin{abstract}
RESUMO
O uso de tecnologias na educação deve levar em conta as especificidades da área do conhecimento para, então, propor a demanda de seu uso pedagógico (SHULMAN, 1986; 1987; KOEHLER; MISHRA, 2005; 2008; OLIVEIRA; PICONEZ, 2016). Na Educação a Distância (EaD), os processos, metodologias e materiais costumam ser bastante padronizados, por questões de tempo e custos de produção. O presente artigo tem como objetivo identificar as práticas pedagógicas na EaD consideradas adequadas às áreas de conhecimento, a partir da visão de professores, alunos e mediadores. Para tanto, está em desenvolvimento uma pesquisa institucional em uma universidade pública virtual no Estado de São Paulo, que propõe o desenvolvimento de um modelo de oferta de disciplinas com base nas especificidades de cada área do conhecimento, tendo como base a tabela da Capes. Assim, após a organização das disciplinas ofertadas na instituição de acordo com as áreas do conhecimento, foram realizados grupos focais e aplicação de questionários com o público da universidade para o levantamento das práticas pedagógicas mais adequadas a cada área. Será proposto um conjunto de práticas pedagógicas para cada área e espera-se que uma nova definição de modelo de oferta de disciplinas, com a participação de toda a comunidade acadêmica, gere possibilidades acordadas ao modelo pedagógico adotado pela instituição e que também sirvam de parâmetro inclusive para outras instituições, além de promover a melhoria da organização interna da instituição no processo de aprendizagem dos alunos.
\end{abstract}

PALAVRAS-CHAVE: Educação. Educação a distância. Tecnologia. Prática Pedagógica.

\footnotetext{
${ }^{1}$ Doutora em Educação - Universidade Estadual de Campinas (UNICAMP). Campinas, SP - Brasil. Docente Universidade Virtual do Estado de São Paulo (UNIVESP). São Paulo, SP - Brasil. E-mail: monica.garbin@gmail.com

${ }^{2}$ Doutor em Educação - Universidade de São Paulo (FE/USP). São Paulo, SP - Brasil. Designer Instrucional Universidade Virtual do Estado de São Paulo (UNIVESP). São Paulo, SP - Brasil. Professor do Ensino Superior Faculdade de Tecnologia de São Paulo (FATEC) - São Paulo, SP - Brasil. E-mail: edisontrombeta@gmail.com Submetido em: 02/08/2019 - Aceito em: 09/01/2020
} 


\title{
ABSTRACT
}

The use of technologies in learning must consider the specificity the knowledge area and then propose a demand for its pedagogical use (SHULMAN, 1986, 1987; KOEHLER; MISHRA, 2005; 2008; OLIVEIRA; PICONEZ, 2016). In distance education, the processes, methodologies, and contents are usually quite standardized, due to production time and costs. This paper aims to identify best pedagogical practices in the distance education, considering a vision of teachers, students and tutors. For that, an institutional research is being developed at a virtual public university in the State of São Paulo, Brazil, which proposes the development of a model of course considering the specificities of each knowledge area, based on the Capes table. Thus, after the organization of the courses offered at the institution according to the areas of knowledge, focus groups and questionnaires were applied with the university public, in order to survey the pedagogical practices most appropriate to each area. For each area of knowledge, a set of pedagogical practices will be proposed, and it is expected that a new definition of the supply model of courses, with the participation of the entire academic community, will generate possibilities according to the pedagogical model adopted and also will serve as parameter to other institutions, as well as promoting the improvement of the internal organization for the students learning process.

KEYWORDS: Education. Distance education. Technologies. Pedagogical practice.

\section{RESUMEN}

El uso de las tecnologías en la educación debe considerar las especificidades del área de conocimiento y luego proponer la demanda para su uso pedagógico (SHULMAN, 1986; 1987; KOEHLER; MISHRA, 2005; 2008; OLIVEIRA; PICONEZ, 2016). En la educación a distancia, los procesos, las metodologías y los materiales suelen estar muy estandarizados, debido al tiempo y a los costos de producción. El objetivo de este artículo es identificar las prácticas pedagógicas en educación a distancia consideradas apropiadas para las áreas de conocimiento, considerando la visión de profesores, estudiantes y mediadores. Para tanto, se está desarrollando una investigación institucional en una universidad pública virtual en el estado de São Paulo (Brasil), que propone el desarrollo de un modelo de ofrecimiento de asignatura que considere las especificidades de cada área de conocimiento, basado en la tabla de Capes. De este modo, después de organizar las asignaturas ofrecidas por la institución según las áreas de conocimiento, se realizaron grupos focales y cuestionarios con el público de la universidad, a fin de estudiar las prácticas pedagógicas más adecuadas para cada área. Se propondrá un conjunto de prácticas pedagógicas para cada área y se espera que una nueva definición del modelo de ofrecimiento de asignaturas, con la participación de toda la comunidad académica, genere posibilidades de acuerdo con el modelo pedagógico adoptado por la institución y también sirva como parámetro para otras instituciones, además de promover la mejora de la organización interna de la institución en el proceso de aprendizaje de los estudiantes.

PALAVRAS-CLAVE: Educación. Educación a distancia. Tecnologías. Prácticas pedagógicas.

\section{INTRODUÇÃO}

A Universidade Virtual do Estado de São Paulo é uma universidade pública do estado de São Paulo e no ato de sua criação sua missão foi pautada em promoção do conhecimento como bem público, universalização do acesso à educação formal e à educação para cidadania, aplicação de metodologias inovadoras e uso intensivo das tecnologias de informação e de comunicação aplicadas à educação.

Em 2017, a instituição iniciou um processo de expansão que resultou no aumento do número de vagas e o início de novos cursos. Por tratar-se de uma instituição que oferece cursos na modalidade de Educação a Distância (EaD), há uma constante discussão sobre como a apresentação dos conteúdos deve ocorrer para promover a aprendizagem: quais práticas pedagógicas em educação a distância são adequadas para uma formação com qualidade?

\author{
(C) ETD- Educação Temática Digital Campinas, SP
}

v. 23

n.1 p. $44-63$

jan. /mar.2021 
A partir dessa inquietação, em meados 2018, foi iniciado um projeto institucional a fim de investigar as melhores práticas pedagógicas para a promoção da aprendizagem na educação a distância, tomando como hipótese que as especificidades de cada área do conhecimento devem ser consideradas. Para tanto, optou-se por adotar o conceito de grandes áreas de conhecimento da Capes (Coordenação de Aperfeiçoamento de Pessoal de Nível Superior), pelo fato de a universidade oferecer cursos com especificidades diversas e, além disso, haver propostas para ampliação da oferta de cursos.

Diante deste contexto, o objetivo deste artigo é identificar as práticas pedagógicas em educação a distância consideradas mais adequadas para cada área de conhecimento, levando em consideração os diversos sujeitos participantes dos processos de ensino e de aprendizagem na instituição investigada: professores, alunos, supervisores e mediadores.

\section{REFERENCIAL TEÓRICO}

A EaD, conforme retomada de Oliveira (2019), é reconhecida como modalidade de ensino pela Lei de Diretrizes e Bases da Educação Nacional, mas somente com o decreto 5622 de 2005 ela foi regulamentada. Desde sua instituição, foram divulgadas uma resolução em 2016 e um novo decreto em 2017, que revoga completamente o de 2005. Além disso, em 2019, por meio da portaria $n^{\circ} 90$ da Capes, iniciam-se as possibilidades para oferta de programas de pós-graduação stricto sensu na modalidade a distância. Nota-se, com isso, que a discussão sobre a $\mathrm{EaD}$ se faz importante, garantindo que as práticas pedagógicas desenvolvidas estejam focadas efetivamente na aprendizagem dos alunos.

Atualmente, no Brasil, a EaD é definida como:

[...] a modalidade educacional na qual a mediação didático-pedagógica nos processos de ensino e aprendizagem ocorra com a utilização de meios e tecnologias de informação e comunicação, com pessoal qualificado, com políticas de acesso, com acompanhamento e avaliação compatíveis, entre outros, e desenvolva atividades educativas por estudantes e profissionais da educação que estejam em lugares e tempos diversos (BRASIL, 2017).

Oliveira (2019) argumenta que uma característica brasileira da EaD é que, até 2017, estavam previstos momentos presenciais obrigatórios para cursos ofertados nesta modalidade. Segundo o autor, no Brasil, existe a noção de que a obrigatoriedade da presença no polo comprovava-se "que ele mesmo (aluno) que fizera a prova ou defendera o trabalho e, consequentemente, que ele próprio desempenhara as demais atividades a distância e teria aprendido" (OLIVEIRA, 2019, p. 24). Com a mudança, a importância dada aos polos de apoio presencial também se modifica, não sendo estritamente obrigatória a sua existência na oferta de um curso nessa modalidade. 
Belloni (2009) sugere que a EaD tenha passado por três fases, ou modelos essenciais, definidos de acordo com as tecnologias disponíveis em cada época para promover a interação entre professor e aluno. O primeiro é o ensino por correspondência, em que os alunos recebiam o material por correio, assim como encaminhavam dúvidas e atividades também por correio. $\mathrm{O}$ ensino se caracterizava por ser essencialmente individual. O segundo modelo foi desenvolvido por volta de 1960 para a educação das massas e, portanto, com enfoques behaviorista e industrialista, sendo os meios tecnológicos principais: documentos impressos, programas de áudio e vídeo divulgados por broadcasting ou fitas de cassetes. O terceiro modelo surge na década de 1990 com a criação de ferramentas web e seu diferencial é que a interação possibilita a personalização. $O$ último modelo utiliza todos os meios dos anteriores, mais as Novas Tecnologias de Informação e Comunicação (NTICs), permitindo novas formas de ensinar e de aprender.

Moore e Kearsley (2013) concordam com a autora quanto às novas possibilidades advindas das NTICs e indicam que esse movimento permitiu uma intensificação de cursos oferecidos nessa modalidade, quando universidades, como o Online Campus do Instituto de Tecnologia de Nova Iorque e a International School of Information Management passaram a ofertar cursos e programas baseados na internet.

Atualmente, no Brasil, os dados divulgados pelo Censo de Educação Superior (BRASIL, 2018) demonstram que o número de matriculados em cursos presenciais ainda é superior ao da modalidade a distância; no entanto, o de vagas oferecidas nesta modalidade superou as do ensino superior presencial. Em 2017 foram 13,5 milhões de vagas oferecidas, sendo 7,1 milhões para cursos na modalidade a distância e 6,4 milhões para a presencial (BRASIL, 2018).

Segundo Oliveira (2019), a EaD popularizou-se também pelas novas possibilidades advindas das tecnologias digitais. Contudo, o autor aponta que o uso de tecnologias num processo de ensino e de aprendizagem deve ter uma intencionalidade pedagógica. Ao incorporar o uso de tecnologia em qualquer modalidade de ensino, é preciso ter seu objetivo claro: "quando a tecnologia e seu uso se tornam generalizados, a tecnologia tende a sair do campo de visão e corre-se o risco de não se avaliar criticamente como ela tem sido utilizada e o motivo das decisões que foram tomadas" (OLIVEIRA, 2019, p. 26). Alguns exemplos podem ser vistos adiante.

Hashey e Stahl (2014) concordam com o autor ao relatar possibilidades para o uso intencional das tecnologias com o objetivo de superar deficiências de aprendizagem e promover a acessibilidade. Numa perspectiva semelhante, Shnaikat e AlQudah (2015) discutem que as tecnologias podem auxiliar o desenvolvimento da aprendizagem online se utilizadas com objetivo pedagógico e em processos mais humanizados. Brooks (2015) nos dá um rol de estratégias vivenciadas em cursos de graduação em História online e híbridos, 
beneficiando professores com ideias para melhores práticas educacionais. Já Baumgartner (2015) relata sua própria experiência como professor de línguas em um curso de graduação, indicando a importância do professor em também ser um designer de conteúdo. Reynolds et al. (2016) destacam estudos com foco no letramento informacional, especificando o uso de uma ferramenta para videoconferência. Kuosa et al. (2016) apresentam ferramentas de visualização interativas: uma que registra e personaliza a visualização dos estudantes a partir de seus acessos e outra que permite analisar automaticamente o conteúdo e identificar tópicos de discussão, a partir da ferramenta de busca. Esses são alguns exemplos de autores que trabalharam e demonstraram como o uso intencional de tecnologias pode facilitar o aprendizado, atentando-se ao papel do professor nesse processo.

A partir dos anos 2000, devido às metodologias ativas e ao uso intensivo das novas tecnologias de informação e comunicação, emergiu o framework Conhecimento Tecnológico Pedagógico de Conteúdo, ou Conhecimento Pedagógico dos Conteúdos Tecnológicos (TPACK). Consiste, de forma resumida, em como utilizar a tecnologia nos processos de ensino e de aprendizagem de determinado assunto específico (KOEHLER; MISHRA, 2005; 2008).

Lee Shulman (1986; 1987) apontava, desde a década de 1980, duas pedras fundamentais da ação docente: conhecimento de conteúdo (conceitos e procedimentos relativos às áreas específicas do saber) e conhecimento pedagógico (voltado às práticas de ensino, estratégias de aprendizagem, didática, avaliação, currículo etc.). O conjunto desses campos é o Conhecimento Pedagógico do Conteúdo (como promover a aprendizagem em determinada área do conhecimento específico).

O acréscimo do Conhecimento Tecnológico à estrutura de Shulman aponta para um processo guiado tanto pelos conhecimentos pedagógicos e de conteúdo quanto pelos tecnológicos. Ou seja: assim como há uma didática para cada área do conhecimento, há também apropriações tecnológicas peculiares para o ensino desses conteúdos. Segundo Oliveira e Piconez (2016), desta maneira, não há uma estratégia pedagógica única que possa ser válida, indistintamente, para todos os contextos de ensino e de aprendizagem. Há variadas combinações ou tessituras dos elementos componentes do TPACK para apoiar determinados espaços de ensino e de aprendizagem.

Estas reflexões a respeito do uso intencional das tecnologias são essenciais nos processos de ensino e de aprendizagem a distância. E, neste contexto, três eixos parecem fundamentais no embasamento dos debates, especialmente a respeito da educação pública apoiada pelo uso das tecnologias: "participação na sociedade", "inteligência coletiva/conectada e metodologias inovadoras" e "protagonismo discente".

A participação na sociedade é um dos pilares da educação a distância, especialmente quando se pensa em democratização e abertura, uma vez que os conteúdos produzidos e

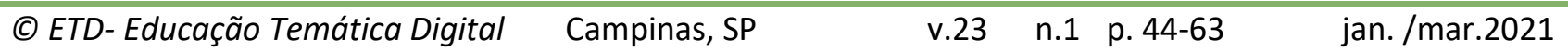


produtores da aprendizagem são disponibilizados por meio da internet, com uso e reuso no tempo e no espaço peculiares de cada usuário/aluno. São novas concepções de espaço e de tempo, proporcionadas por universidades virtuais, que são fundamentais na expansão da educação superior, especialmente para atingir estudantes que, por exemplo, precisam conciliar necessidades pessoais e profissionais.

Há uma correlação clara com a autonomia de Freire (2015): a prática educativa não pode mais ter foco na transmissão de conhecimento, mas sim na criação de possibilidades para sua produção e construção pelos estudantes, com apoio dos professores e demais atores do processo educacional. O conhecimento da realidade dos educandos e de seus saberes prévios é condição sine qua non, de forma a materializar uma educação ao mesmo tempo democratizadora e de respeito às especificidades culturais e regionais. Este fator também vai ao encontro do que aponta Santos (2010, p. 55), em direção a "uma reforma criativa, democrática e emancipatória da universidade pública".

Nesse caráter de expansão e democratização, é fundamental também refletir e materializar estratégias de construção coletiva e conectada dos conhecimentos. Trata-se de utilizar as redes de aprendizagem a fim de permitir interações com os seus pares, professores, mediadores e demais atores do processo educacional, bem como gerar aprendizagem de forma contínua, com apoio dos dispositivos tecnológicos e os recursos. As redes de interações conectadas que se formam entre pessoas, conteúdos e dispositivos, em contínuo processo de colaboração e cooperação tendem a fomentar a inteligência coletiva (LÉVY, 1999).

Por fim, é mote destas novas formas de ensino-aprendizagem, a aplicação intencional de metodologias inovadoras, especialmente as que permitam que os alunos sejam sujeitos de suas próprias aprendizagens. Parte-se de bases como Dewey (1978), de aprendizagem pela experiência, Vygotsky (1984), cujo foco é na interação social, e o já citado Freire (2015), que prima pela autonomia. São fundamentos que se integram ao cenário da cultura digital e da aprendizagem em rede e deixam clara a necessidade de criação de oportunidades didáticas de interação, colaboração, trabalho em equipe, criticidade, empatia etc. A intenção é gerar engajamento no qual situações didáticas combinem atividades, desafios e informações por meio de recursos selecionados e adequados. 


\section{MODELO PEDAGÓGICO INSTITUCIONAL}

No modelo pedagógico da instituição, as disciplinas são oferecidas bimestralmente e são articuladas no desenvolvimento de um projeto que integra os conhecimentos e os articula com as práticas profissionais do curso. Todo o processo ocorre num Ambiente Virtual de Aprendizagem (AVA). Assim, os currículos contemplam disciplinas cujos conteúdos teóricos são articulados a situações e/ou problemas reais durante o desenvolvimento do projeto integrador colaborativo.

O modelo de produção adotado é o de curadoria de conteúdos, ou seja, os professores, com o apoio da equipe, selecionam recursos e desenvolvem um roteiro de aprendizagem de modo a integrar os materiais. Há também a possibilidade de gravação de videoaulas, já que a universidade possui um canal de televisão que também funciona pelo YouTube, e cujo estúdio localiza-se na TV Cultura, na cidade de São Paulo. Para compor tais roteiros são utilizados os seguintes recursos, após pesquisa e a curadoria do professor:

- Recursos educacionais abertos (REA) - produzidos pela universidade, com orientação do professor da disciplina. Normalmente, possuem algum tipo de interação.

- Vídeos - Podem ser: a) videoaulas tradicionais - expositivas gravadas em estúdio e normalmente com o apoio de slides; b) videoaulas diferenciadas - produzidas pela instituição e gravadas externas ao estúdio, com auxílio de roteiro; c) videoaulas com resolução de exercícios - gravadas com o desenvolvimento de algumas atividades pelo docente; d) vídeos do YouTube e outros canais - indicados pelo docente; e) Webconferências - momento síncrono realizadas por mediadores ou professores.

- Textos - São oferecidas bibliotecas virtuais para os estudantes, e os professores também podem indicar textos disponíveis de maneira aberta na Internet.

- Fóruns de discussão - Podem ser: a) como apoio à solução de dúvidas; b) como ferramenta para uma discussão dirigida.

- Atividades - Podem ser: a) avaliativas - cuja resolução é corrigida e uma nota atribuída na média final; b) apoio ao estudo - que compreende uma série de atividades disponibilizadas para auxiliar na resolução das atividades avaliativas.

- Orientações de estudos no AVA - São orientações dadas aos estudantes para focar seus estudos ou para contextualizar determinado problema relacionado ao conteúdo. Atualmente, a universidade adota um único modelo de disciplina para todas as áreas de conhecimento, sem considerar possíveis especificidades. Essa padronização gera conflito e retrabalho nas áreas internas, quando é necessário realizar alguma adequação. Nos primeiros quatro anos da universidade, ocorreram discussões constantes sobre a forma de disponibilização dos conteúdos, com apresentação de propostas e sugestões em relação ao material didático das disciplinas, tanto do ponto de vista dos professores, quanto da 
aprendizagem dos estudantes. Esses aspectos buscam uma maior interação entre estudantes e professores, conteúdos mais aplicados e práticos e ferramentas que engajem o trabalho coletivo e colaborativo, visto que todos os cursos são ofertados em um mesmo AVA.

\section{MÉTODO}

Este artigo é resultado de uma das etapas realizadas num projeto em desenvolvimento na instituição desde julho de 2018. Sua condução é baseada na metodologia do Design Centrado em Humanos (HCD - Human Centered Design) (PLATTNER; MEINEL; LEIFER, 2011; BROWN, 2008) e objetiva a criação de modelos de disciplinas contemplando práticas pedagógicas adequadas para a aprendizagem em cada área do conhecimento. Para este artigo serão apresentados os dados obtidos nos grupos focais, realizados como terceira etapa do projeto.

A partir da divisão das disciplinas ofertadas na universidade por área do conhecimento, foram realizados três grupos focais para cada uma delas, sendo:

1. Grupo de professores - foram selecionados os professores autores de disciplinas há mais tempo na universidade ou que são constantemente bem avaliados pelos estudantes.

2. Grupo de alunos - foram selecionados aleatoriamente, dentre aqueles que indicaram previamente a disponibilidade de participar de grupo focal.

3. Grupo de mediadores e supervisores - foram selecionados aqueles que estavam atuando há mais tempo na universidade ou que são constantemente bem avaliados pelos estudantes.

As questões que compunham cada grupo focal buscavam identificar as práticas pedagógicas e os recursos mais adequados a cada área de conhecimento. Em se tratando de um contexto de educação a distância, as práticas pedagógicas estão intimamente relacionadas ao uso de recursos digitais para a promoção da aprendizagem, conforme mencionado anteriormente.

Neste sentido, o objetivo deste artigo é identificar as práticas pedagógicas em educação a distância consideradas mais adequadas para as especificidades de cada área do conhecimento, sob a perspectiva dos estudantes, professores, supervisores e mediadores da universidade em questão. Espera-se que sejam fornecidos dados que embasem discussões sobre a qualidade da oferta de ensino na $\mathrm{EaD}$, já que como já foi dito, trata-se de uma modalidade em crescimento exponencial no Brasil. 
Trata-se, então, de uma análise de cunho qualitativo. Creswell (2007, p. 186-187) aponta que a pesquisa qualitativa "ocorre em cenário natural [...] é fundamentalmente interpretativa [...] e o seu pesquisador usa raciocínio complexo multifacetado, interativo e simultâneo para a interpretação dos dados". Segundo Silverman (2009, p. 51) "um ponto forte sobre a pesquisa qualitativa é que ela usa dados que ocorrem naturalmente para encontrar as sequências ("como") em que os significados dos participantes ("o quê") são exibidos e, assim, estabelecer o caráter de algum fenômeno". Além disso, o autor aponta que existem 4 (quatro) formas principais para coleta de dados: observação; análise de textos e documentos; entrevistas e grupos focais; e gravações em áudio e vídeo.

A análise de dados qualitativos, conforme indica Creswell (2007, p. 194) "envolve preparar os dados para análise, conduzir análises diferentes, aprofundar-se cada vez mais no entendimento dos dados, fazer representação dos dados e fazer uma interpretação do significado mais amplo dos dados". De acordo com o autor, os dados desta pesquisa foram organizados por área de conhecimento, articulando as impressões obtidas em cada grupo de participantes, estabelecendo a relação entre as práticas pedagógicas e recursos usados. Além disso, buscou-se também estabelecer conexões entre as áreas de conhecimentos, sobre o que é comum entre elas.

\section{RESULTADOS}

De forma geral, foi possível estabelecer conexões entre os apontamentos nas diferentes áreas, especialmente no que se refere aos textos, aos fóruns de discussões e orientações de estudos. Quanto às bibliotecas virtuais e textos em geral, os alunos indicaram que preferem que sejam mais curtos e que possam ser impressos no papel. Sobre este recurso, apontam que por vezes optam por adquirir a obra completa indicada pelo docente, o que faz com que os textos disponíveis de maneira aberta na internet sejam vistos de forma positiva, pois são mais acessíveis à leitura impressa, uma vez que não são todos os textos das bibliotecas que permitem a impressão.

Quanto aos fóruns de discussão, houve consenso entre os participantes que precisam de adequação para que sejam espaços proveitosos na resolução de dúvidas e no compartilhamento de ideias. Atualmente, estão divididos por disciplina e polo, e a sugestão é que sejam compostos por um número maior de participantes para que a interação ocorra, além dos limites físicos do polo.

Em relação às orientações de estudos, de forma geral, os participantes indicaram a importância ao auxiliarem a associação dos conhecimentos tratados durante o bimestre, bem como na sua compreensão, delimitando os principais conteúdos e aspectos da disciplina. Professores, supervisores e mediadores apontaram a necessidade de utilizar neste recurso 
diversas linguagens além da textual, como a inserção de infográficos e vídeos, que permitem um maior destaque e interatividade com determinado conteúdo.

Quanto aos vídeos, houve um ponto comum a todos os grupos focais sobre webconferências realizadas por professores autores com o propósito de revisão de conteúdo, sempre na semana que antecede às provas. Tal dinâmica traz um viés de aproximação com os alunos, além da oportunidade de esclarecimento das dúvidas. Finalmente, em todos os grupos focais houve a mesma indicação em relação ao tempo das videoaulas, que deveria variar de 15 a 30 minutos.

\subsection{Engenharias}

$\mathrm{Na}$ área de Engenharias, são 35 disciplinas, todas pertencentes aos cursos de Engenharia de Produção e Engenharia de Computação:

Tabela 1 - Distribuição de disciplinas por área de conhecimento - Engenharias

\begin{tabular}{|c|c|c|c|c|c|c|}
\hline Área & Eng. Produção & Eng. Computação & $\begin{array}{c}\text { Lic. em } \\
\text { Matemática }\end{array}$ & Pedagogia & Gestão Pública & Total \\
\hline Engenharias & 26 & 9 & 0 & 0 & 0 & 35 \\
\hline
\end{tabular}

Durante a realização dos grupos focais desta área de conhecimento, foi possível compreender que o formato de videoaulas contribui para o aprendizado, contudo os participantes apontam a necessidade de os vídeos abordarem os conhecimentos de maneira mais prática, tal como são contemplados nos vídeos diferenciados. Inclusive apontam que estes, aliados aos REAs, possibilitam uma diversidade de linguagens que facilita a atenção aos conteúdos, bem como o seu aprendizado. Os estudantes ressaltam a importância da disponibilização dos slides das videoaulas para impressão e estudo enquanto as assistem.

Os mediadores e supervisores apontam que disciplinas com maior conteúdo teórico pedem o formato de vídeo mais tradicional, em contrapartida as outras, mais práticas, precisam vir acompanhadas de simulações - não como elemento obrigatório, apenas como um estímulo a aprendizagem do aluno. Avaliam que as disciplinas "mais difíceis" (com maior número de reprovados, por exemplo) poderiam ter um número maior de vídeos disponibilizados. Atualmente, as disciplinas variam o número de vídeos, de acordo com a sua carga horária (GARBIN; OLIVEIRA, 2019). 
Foi unânime a todos os participantes sobre a necessidade de incluir elementos que demonstrem como os conhecimentos teóricos são aplicados na prática, em um processo ou contexto profissional relacionado às Engenharias. Isso pode ser incorporado tanto nas videoaulas quanto por meio dos REA. Neste sentido, fazem avaliação similar às atividades, indicando a necessidade de muitas atividades de apoio, ou seja, exercícios resolvidos, para suporte ao aprendizado. Destacam também a necessidade de atividades dissertativas, evitando o uso de atividades de múltipla-escolha.

Em suma, foi possível perceber que as práticas pedagógicas específicas desta área na EaD devem promover a integração da teoria à prática, de forma que demonstrem aos estudantes como os conhecimentos trabalhados nas disciplinas são utilizados em um contexto prático. Há uma grande dificuldade dos estudantes na compreensão de determinados conteúdos quando são trabalhados de forma teórica e abstrata. Professores que estimulam essa relação teoria-prática são mais eficientes na promoção da aprendizagem. Deve ser incentivado o uso de exercícios dissertativos, que promovem a reflexão de conhecimentos pelos estudantes, em conjunto com exercícios resolvidos, que permitem que os estudantes compreendam os caminhos que devem seguir para a resolução da atividade.

\subsection{Ciências Sociais Aplicadas}

$\mathrm{Na}$ área de Ciências Sociais Aplicadas, são ao todo 45 disciplinas, distribuídas nos cursos de Engenharia de Produção, Engenharia de Computação e Gestão Pública:

Tabela 2 - Distribuição de disciplinas por área de conhecimento - Ciências Sociais Aplicadas

\begin{tabular}{|l|c|c|c|c|c|c|}
\hline \multicolumn{1}{|c|}{ Área } & $\begin{array}{c}\text { Eng. } \\
\text { Produção }\end{array}$ & $\begin{array}{c}\text { Eng. } \\
\text { Computação }\end{array}$ & $\begin{array}{c}\text { Lic. em } \\
\text { Matemática }\end{array}$ & Pedagogia & $\begin{array}{c}\text { Gestão } \\
\text { Pública }\end{array}$ & Total \\
\hline $\begin{array}{l}\text { Ciências Sociais } \\
\text { Aplicadas }\end{array}$ & 19 & 6 & 0 & 0 & 18 & 43 \\
\hline
\end{tabular}

\section{Fonte: autores}

Nestes grupos focais, os estudantes preferem as videoaulas expositivas e tradicionais tendo o docente da disciplina como interlocutor principal, enquanto os supervisores e mediadores entendem que as videoaulas diferenciadas podem auxiliar na compreensão e exemplificação de conceitos e conteúdos mais práticos. Os docentes concordam que as aulas expositivas são essenciais e que podem ser mescladas, "sem exagero", às diferenciadas. Dessa forma, as videoaulas tradicionais devem ser intercaladas com aquelas de conteúdos mais práticos, bem como com os REA, dando maior atenção ao conteúdo que está sendo trabalhado. Indicam também que os recursos educacionais da instituição promovem a possibilidade de exercitar os conteúdos. 
Com relação aos textos e às bibliotecas, os docentes afirmam que preferem escrever o próprio conteúdo, pela dificuldade de encontrar textos específicos sobre cada tópico a ser desenvolvido na disciplina. Quanto às bibliotecas virtuais, os estudantes afirmam utilizar apenas quando há indicação por parte dos docentes. Em relação às atividades para a avaliação, os docentes ressaltam a sua importância para melhor desenvolvimento do conteúdo pelos estudantes; mediadores e supervisores acreditam que as atividades de múltipla-escolha são melhores do que as dissertativas. Os alunos afirmam que se sentem mais seguros para responder às atividades de múltipla-escolha.

Finalmente, sobre as práticas pedagógicas específicas desta área para EaD foi possível notar que o modelo de videoaula expositiva é bastante importante, mas deve ser intercalado com outros recursos que utilizem linguagens diversas. Assim, os conceitos mais teóricos devem ser acompanhados por recursos que promovam sua contextualização. Quanto às atividades, nota-se que podem ser objetivas quando determinado conteúdo não precisa de aprofundamento. No entanto, questões abertas permitem que o aluno desenvolva o raciocínio e faça deduções e, nesta área, é preciso permitir que o aluno discorra sobre os temas trabalhados.

\subsection{Ciências Exatas e da Terra}

Na área de Ciências Exatas e da Terra, são ao todo 64 disciplinas, distribuídas em todos os cursos oferecidos, com mais destaque nos cursos de Engenharia:

Tabela 3 - Distribuição de disciplinas por área de conhecimento - Ciências Exatas e da Terra

\begin{tabular}{l|c|c|c|c|c|c|}
\multicolumn{1}{|c|}{ Área } & $\begin{array}{c}\text { Eng. } \\
\text { Produção }\end{array}$ & $\begin{array}{c}\text { Eng. } \\
\text { Computação }\end{array}$ & $\begin{array}{c}\text { Lic. em } \\
\text { Matemática }\end{array}$ & Pedagogia & $\begin{array}{c}\text { Gestão } \\
\text { Pública }\end{array}$ & Total \\
\hline $\begin{array}{l}\text { Ciências Exatas e da } \\
\text { Terra }\end{array}$ & 20 & 25 & 14 & 1 & 4 & 64 \\
\hline \multicolumn{2}{|c|}{ Fonte: autores } \\
\hline
\end{tabular}

Em relação às videoaulas, os alunos e professores da área preferem as que utilizam recursos mais tradicionais como slides e/ou a lousa para demonstrar algum exercício. Foi ressaltado por todos os participantes a importância de videoaulas que mostrem a resolução de exercícios na lousa com passo a passo para o aluno. Outro aspecto levantado pelos participantes foi a importância das videoaulas diferenciadas para explorar os conteúdos de forma mais interativa e apoiar a teoria contemplada nas videoaulas expositivas. Já quanto aos recursos educacionais, professores, supervisores e mediadores afirmam que eles auxiliam no aprendizado dos alunos desde que sejam utilizados para demonstrar a teoria com a aplicação da prática do aluno. Além disso, o aspecto mais destacado por esses participantes foi a necessidade de aproximação da linguagem matemática ao estudante, ou seja, fazê-lo compreender o raciocínio matemático. 
Os estudantes apontam a necessidade de atividades resolvidas, para que consigam desenvolver as voltadas para avaliação. Os professores indicam que para a compreensão dos conceitos dessa área é necessário utilizar a repetição, por meio de listas de exercícios. Isso pôde ser comprovado com a indicação de disciplinas que utilizam esses recursos para promoção da aprendizagem.

Assim, as práticas pedagógicas que devem ser incentivadas nessa área na $\mathrm{EaD}$ são as que aproximam a linguagem matemática e/ou das ciências exatas ao aluno. Professores que estimulam essa aproximação são mais eficientes no ensino de determinado conteúdo. Recursos que demonstram a resolução de exercícios também foram muito citados ao longo dos grupos focais, como videoaulas, recursos educacionais e atividades resolvidas.

\subsection{Ciências Humanas}

$\mathrm{Na}$ área de Ciências Humanas, há ao todo 61 disciplinas, tendo mais destaque no curso de Pedagogia, que aparece com 48 disciplinas nesta área:

Tabela 4 - Distribuição de disciplinas por área de conhecimento - Ciências Humanas

\begin{tabular}{|l|c|c|c|c|c|c|}
\hline Área & $\begin{array}{c}\text { Eng. } \\
\text { Produção }\end{array}$ & $\begin{array}{c}\text { Eng. } \\
\text { Computação }\end{array}$ & $\begin{array}{c}\text { Lic. em } \\
\text { Matemática }\end{array}$ & Pedagogia & $\begin{array}{c}\text { Gestão } \\
\text { Pública }\end{array}$ & Total \\
\hline $\begin{array}{l}\text { Ciências } \\
\text { Humanas }\end{array}$ & 1 & 0 & 11 & 48 & 1 & $\mathbf{6 1}$ \\
\hline
\end{tabular}

Fonte: autores

Da mesma forma que os estudantes da área de Ciências Sociais Aplicadas, os de Ciências Humanas sentem necessidade de que as videoaulas sejam gravadas pelos professores da disciplina, utilizando recursos mais tradicionais, como slides. Tais modelos de aula devem apresentar uma frequência semanal. As videoaulas com conteúdos mais interativos são vistas como materiais que apoiam e dão concretude a determinada teoria, assim como os recursos educacionais, que também auxiliam no aprendizado dos alunos, desde que utilizem a teoria na aplicação prática. Segundo uma das alunas participantes, esses recursos "são uma ótima forma de testar o que foi aprendido e fixar os conhecimentos".

No que tange aos textos utilizados nas disciplinas, os professores apontam certa dificuldade em utilizar material fora dos contextos das bibliotecas. Quanto às atividades, todos consideram que são extremamente úteis para reflexão dos conteúdos aprendidos, desde que sejam dissertativas e promovam a integração dos conhecimentos trabalhados no bimestre. Já com relação às provas presenciais, os estudantes demonstraram preferirem as atividades dissertativas às atividades de múltipla escolha, pois, segundo eles, tais atividades permitem refletir sobre todo o conteúdo aprendido. 
Pela essência da área, as práticas pedagógicas devem ter como foco a reflexão e a discussão das complexidades da sociedade, tendo o ser humano como principal objeto de estudo. Assim, as videoaulas gravadas pelos professores são essenciais para a condução do pensamento, diante dos recursos usados na disciplina, bem como atividades contextualizadas em determinadas situações do campo de trabalho futuro, que promovam a escrita reflexiva pelos estudantes. Recursos interativos são importantes e podem promover a aproximação entre as teorias e reflexões trazidas pelos professores, à prática profissional do curso.

\subsection{Linguística, Letras e Artes}

A área Linguística, Letras e Artes contém um número menor de disciplinas em relação às demais áreas:

Tabela 5 - Distribuição de disciplinas por área de conhecimento - Linguística, Letras e Artes

\begin{tabular}{l|c|c|c|c|c|c|}
\hline \multicolumn{1}{|c|}{ Área } & $\begin{array}{c}\text { Eng. } \\
\text { Produção }\end{array}$ & $\begin{array}{c}\text { Eng. } \\
\text { Computação }\end{array}$ & $\begin{array}{c}\text { Lic. em } \\
\text { Matemática }\end{array}$ & Pedagogia & $\begin{array}{c}\text { Gestão } \\
\text { Pública }\end{array}$ & Total \\
\hline $\begin{array}{l}\text { Linguística, Letras e } \\
\text { Artes }\end{array}$ & 1 & 1 & 1 & 2 & 9 & 14 \\
\hline
\end{tabular}

Os alunos elogiam as videoaulas dessa área do conhecimento, especialmente as que promovem uma linguagem dialógica entre professor e aluno. A respeito das expositivas (professor e slide), afirmam que fazem diferença, pois foram produzidas com o foco no aluno, e não apenas selecionadas pelo professor. Para professores, supervisores e mediadores, a produção das videoaulas deve ter como foco principal o estudante, utilizando um diálogo que capte sua atenção, não apenas visando a transmissão do conteúdo, mas sua contextualização e a inserção de perguntas e atividades durante a videoaula.

Sobre as videoaulas diferenciadas e mais interativas e os REA, os alunos afirmam ser importante a utilização de linguagens e recursos variados para o auxílio na aprendizagem. Segundo a afirmação de uma aluna: "o recurso não substitui a videoaula, mas serve como reforço para o que aprendeu ou mesmo preparo para o que virá". Professores, supervisores e mediadores compartilham da mesma visão e acrescentam que esses recursos são importantes pois há pluralidade de estilos de aprendizagem entre alunos. Além disso, os professores acreditam "que os recursos devem gerar provocação, reflexão e aplicação prática dos conceitos, e não só transmissão de conhecimento". Para eles, as pessoas "não ligam conhecimento à realidade", e o recurso educacional aberto poderia fazer essa ligação. 
Assim, para as práticas pedagógicas nesta área devem ser promovidas situações que ilustrem o conteúdo, por meio de exemplos concretos, como músicas ou reportagens, para que o aluno se engaje no conteúdo. No entanto, materiais mais expositivos também são importantes e necessários para a sistematização de conceitos. É importante que sejam utilizadas diversas linguagens que promovam a reflexão do estudante. De modo geral, os professores sugerem: em vez de um REA que mostre o behaviorismo e os tipos de reforço envolvidos, por que não fazer os alunos pensarem nas vantagens e desvantagens do método na vida real, por exemplo mostrando operários apertando parafusos o dia todo?

\subsection{Multidisciplinar}

$\mathrm{Na}$ área de Multidisciplinar, são ao todo 67 disciplinas, distribuídas em todos os cursos oferecidos, aparecendo com maior destaque nos cursos de Engenharias:

Tabela 7 - Distribuição de disciplinas por área de conhecimento - Multidisciplinar

\begin{tabular}{c|c|c|c|c|c|c|}
\hline \multicolumn{1}{|c|}{ Área } & Eng. Produção & Eng. Computação & $\begin{array}{c}\text { Lic. em } \\
\text { Matemática }\end{array}$ & Pedagogia & Gestão Pública & Total \\
\hline Multidisciplinar & 27 & 15 & 17 & 4 & 4 & 67 \\
\hline & & \multicolumn{2}{|r|}{ Fonte: autores } & & \\
\hline
\end{tabular}

Não diferente da maioria das outras áreas, os estudantes indicam que as videoaulas expositivas estejam presentes, ao menos, uma vez por semana e sejam complementadas pelas diferenciadas, porque estas também conseguem captar a atenção dos estudantes. Em relação aos recursos educacionais abertos, foram apontados como ferramenta eficaz na demonstração de aplicações e mencionam sua importância na fixação do conteúdo. Os professores acreditam que os REAs são estimulantes, possibilitam uma aproximação do estudante com os conteúdos e ajudam a construir as situações-problema. Quanto aos textos, os professores apontam seu apreço por artigos e links da internet, indicando que quando o texto é grande, deve ter figuras e escrita leve para evitar o cansaço do aluno. Finalmente, no que tange as atividades, para os professores, as atividades avaliativas são bons instrumentos para composição de nota e as de apoio são importantes para exercitar os conteúdos. Afirmam preferir as atividades discursivas em detrimento das de múltipla escolha: "o ideal seria a mescla de questões abertas e fechadas, já que ambas preparam tanto para concursos quanto para o dia-a-dia profissional".

De modo geral, a grande preocupação com as disciplinas desta área é em utilizar uma linguagem prática, aplicada ao contexto do curso, bem como fazer pontes com disciplinas futuras. Quanto às atividades, o ideal é que haja mescla de questões abertas e fechadas. As videoaulas devem focar tanto em aspectos que contextualizem os conceitos abordados como mais práticos e expositivos, dependendo do que será trabalhado em cada roteiro.

$\begin{array}{llllll}\text { (c) ETD-Educação Temática Digital Campinas, SP } & \text { v.23 } & \text { n.1 } & \text { p.44-63 jan./mar.2021 }\end{array}$




\section{CONSIDERAÇÕES FINAIS}

O presente artigo faz parte dos dados obtidos num projeto institucional realizado na Universidade Virtual do Estado de São Paulo e teve como objetivo identificar as práticas pedagógicas em educação a distância consideradas adequadas para cada área de conhecimento, levando em consideração os diversos sujeitos participantes do processo.

As etapas descritas neste trabalho foram realizadas durante os meses de julho a outubro de 2018. De forma geral, notou-se que os estudantes sentem necessidade de conteúdos e teorias contextualizadas à sua área de atuação. A partir do desenvolvimento desses conhecimentos, que nos modelos de disciplina não se restringem à teoria e se aliam à formação crítica, se pretende que os alunos sejam sujeitos de sua própria aprendizagem (FREIRE, 2015) e vejam sentido naquilo que aprendem e no papel social da sua futura profissão. A proposição de desafios ou outras maneiras de materializar a teoria vai na direção do engajamento proposto Garbin e Oliveira (2019).

Os alunos também demonstraram a importância da interlocução com seus professores, o que pode e deve ser materializado por meio das NTIC - neste caso, o AVA e outros recursos que a ele podem ser acoplados. Essa necessidade de interação entre os atores do processo educacional, demandada pelos estudantes e também pelos professores, mediadores e supervisores, é o que Lévy (1999) chama de inteligência coletiva. Os modelos de disciplinas gerados devem considerar a formação de redes de interações que conectem pessoas, conteúdos e dispositivos para colaboração e cooperação como um ponto fundamental. A ação humana, tanto na produção dos conteúdos quanto na sua execução junto aos alunos, é fundamental na EaD.

Os esforços da instituição em desenvolver conteúdos cada vez mais dinâmicos e interativos para serem incorporados ao longo das disciplinas foram considerados positivos. Há valorização de modelos diferenciados de videoaula mais adaptados a cada área do conhecimento: as diferenciadas são apontadas como material fundamental para a área de Engenharias, e de apoio para as demais, enquanto que videoaula com resolução de exercício é essencial na área de Ciências Exatas e da Terra. Esse fator confirma o pressuposto do TPACK (KOEHLER; MISHRA, 2008), de que uma mesma tecnologia deve ser aplicada de maneira diferente, com outra intencionalidade educacional, a depender da área de conhecimento à qual se aplica.

Já em relação aos professores, supervisores e mediadores, os apontamentos vão mais na direção de práticas pedagógicas, que é o foco deste trabalho. Eles entendem, que é importante que o material provoque surpresa em seus alunos e que é preciso proporcionar um "espetáculo com conteúdo e reflexão", que não seja vazio e que "só mostre por mostrar". 
É comum, na EaD, que se valorize em excesso o aspecto visual do material didático e não se considere como deveria os aspectos didáticos e instrucionais. Suas falas também indicam que as metodologias inovadoras devem ser valorizadas e aplicadas desde que favoreçam a aprendizagem dos estudantes. Para cada área do conhecimento, uma tecnologia pode ser aplicada segundo certa base educacional, tais quais as desenvolvidas por Dewey (1978), Vygotsky (1984) e Freire (2015). As tecnologias não carregam em si uma única intencionalidade didática: nos modelos de disciplinas adequados às áreas do conhecimento, por exemplo, é possível verificar que as listas de exercícios podem ser utilizadas de formas distintas, ora com mais exercícios de apoio, ora com mais questões dissertativas ou múltiplaescolha. E é a partir dessa identificação das necessidades de ensino e de aprendizagem que os atores do processo educacional podem, de acordo com Oliveira e Piconez (2016), traçar estratégias que combinem elementos didáticos, tecnológicos e de conteúdos para apoiar o processo educacional em cada contexto.

A síntese dos resultados obtidos pode ser observada no quadro a seguir. Espera-se que, com a finalização do projeto, os modelos de disciplinas gerados favoreçam a aprendizagem dos alunos e sirvam de parâmetro inclusive para outras instituições. 
Quadro 1 - Resultados obtidos nos grupos focais

\begin{tabular}{|c|c|c|c|c|c|c|}
\hline Recursos & Engenharias & $\begin{array}{l}\text { Ciências Sociais } \\
\text { Aplicadas }\end{array}$ & $\begin{array}{l}\text { Ciências Exatas e da } \\
\text { Terra }\end{array}$ & Ciências Humanas & Linguística, Letras e Artes & Multidisciplinar \\
\hline REAs & \multicolumn{6}{|c|}{$\begin{array}{l}\text { - Possibilitam a prática de determinado conceito. } \\
\text { - São uma ótima forma de testar o que foi aprendido e fixar os conhecimentos. }\end{array}$} \\
\hline \multirow[t]{2}{*}{ Vídeos } & $\begin{array}{l}\text { - Devem trazer a } \\
\text { prática em relação ao } \\
\text { conceito, com } \\
\text { simulações. }\end{array}$ & $\begin{array}{l}\text { - Videoaulas } \\
\text { tradicionais devem ser } \\
\text { intercaladas com } \\
\text { conteúdos mais práticos, } \\
\text { para maior atenção ao } \\
\text { conteúdo. }\end{array}$ & $\begin{array}{l}\text { - Videoaulas que } \\
\text { mostrem a resolução } \\
\text { de exercícios. } \\
\text { - Videoaulas } \\
\text { diferenciadas que } \\
\text { exploram os } \\
\text { conteúdos de forma } \\
\text { mais interativa. }\end{array}$ & $\begin{array}{l}\text { - Videoaulas gravadas p } \\
\text { fazem a diferença pois for } \\
\text { aluno, e não apenas selec } \\
\text { - Videoaulas com conteı } \\
\text { como materiais que apoia } \\
\text { determinada teoria. }\end{array}$ & $\begin{array}{l}\text { os professores da disciplina } \\
\text { on produzidas com o foco no } \\
\text { onadas pelo professor. } \\
\text { dos mais interativos são vistas } \\
\text { n e dão concretude a }\end{array}$ & $\begin{array}{l}\text { - Videoaulas } \\
\text { expositivas são } \\
\text { necessárias. } \\
\text { - Videoaulas } \\
\text { diferenciadas para } \\
\text { complementar, com } \\
\text { aspectos mais práticos e } \\
\text { expositivo. }\end{array}$ \\
\hline & \multicolumn{6}{|c|}{$\begin{array}{l}\text { - Tempo da videoaula adequado - } 15 \text { a } 30 \text { minutos. } \\
\text { - Webconferências de revisão trazem um viés de aproximação entre professores e alunos, além da oportunidade de esclarecimento das dúvidas. }\end{array}$} \\
\hline $\begin{array}{l}\text { Bibliotecas } \\
\text { virtuais } \\
\text { Textos }\end{array}$ & \multicolumn{6}{|c|}{$\begin{array}{l}\text { - Os alunos preferem textos mais curtos e com a possibilidade de impressão e optam por adquirir a obra completa indicada pelo docente. } \\
\text { - Os textos disponíveis de maneira aberta na internet são vistos de forma positiva, pois são mais acessíveis à leitura impressa. } \\
\text { - Docentes preferem artigos e links da internet, indicando que quando o texto é grande, deve ter figuras e escrita leve para evitar o cansaço do aluno. }\end{array}$} \\
\hline $\begin{array}{ll}\text { Fóruns de } \\
\text { discussão }\end{array}$ & \multicolumn{6}{|c|}{ - Reorganização do ambiente para que sejam espaços para resolução de dúvidas e no compartilhamento de ideias. } \\
\hline Atividades & $\begin{array}{l}\text { - Listas de } \\
\text { exercícios resolvidos. } \\
\text { - Listas de } \\
\text { atividades } \\
\text { dissertativas. }\end{array}$ & $\begin{array}{l}\text { - Podem ser objetivas, } \\
\text { mas questões abertas } \\
\text { são necessárias para que } \\
\text { o aluno desenvolva o } \\
\text { raciocínio e faça } \\
\text { deduções. }\end{array}$ & $\begin{array}{l}\text { - Listas de exercícios } \\
\text { resolvidos. } \\
\text { - Listas de atividades } \\
\text { dissertativas. }\end{array}$ & $\begin{array}{l}\text { - Dissertativas e que } \\
\text { promovam a integração } \\
\text { dos conhecimentos } \\
\text { trabalhados ao longo do } \\
\text { bimestre. }\end{array}$ & $\begin{array}{l}\text { - Complementam e } \\
\text { sistematizam o material das } \\
\text { aulas e devem ser ampliadas } \\
\text { as possibilidades de uso. }\end{array}$ & $\begin{array}{l}\text { - Atividades discursivas } \\
\text { em detrimento das de } \\
\text { múltipla escolha. }\end{array}$ \\
\hline $\begin{array}{l}\text { Organização } \\
\text { dos conteúdos } \\
\text { no AVA }\end{array}$ & \multicolumn{6}{|c|}{$\begin{array}{l}\text { - Todos indicaram a importância deste recurso pois auxilia na associação dos conhecimentos tratados durante o bimestre, bem como na sua compreensão, } \\
\text { delimitando os principais conteúdos e aspectos da disciplina. }\end{array}$} \\
\hline
\end{tabular}




\section{REFERÊNCIAS}

BAUMGARTNER, Karin. Strategies for hybrid course design in second-year German. Die Unterrichtspraxis / Teaching German, v. 48, n. 2, p. 211-228, 2015.

BELLONI, Maria Luiza. Educação a distância. São Paulo: Autores Associados, 2009.

BRASIL. Decreto no 9057, de 25 de maio de 2017. Regulamenta o art. 80 da Lei no 9.394, de 20 de dezembro de 1996, que estabelece as diretrizes e bases da educação nacional. Brasília, DF: Diário Oficial da União, 26 maio 2017.

BRASIL. Ministério da Educação - MEC. (2014). Censo da Educação Superior. Brasília, 2018.

BROOKS, Michael. Developing effective undergraduate online history courses: an experiential model. Teaching History: A Journal of Methods, v. 40, n. 2, p. 73-86, 2015.

BROWN, Tim. Design thinking. Harvard Business Review, v. 86, n. 6, p. 84-92, 2008.

CRESWEL, John. W. Projeto de pesquisa: métodos qualitativo, quantitativo e misto. Porto Alegre: Artmed, 2007.

DEWEY, John. Vida e educação. 10. ed. São Paulo: Melhoramentos, 1978.

FREIRE, Paulo. Pedagogia da autonomia: saberes necessários à prática educativa. 51. ed. Rio de Janeiro: Paz e Terra, 2015.

GARBIN, Mônica C.; OLIVEIRA, Édison Trombeta. Práticas docentes na educação a distância: um olhar sobre as áreas do conhecimento. Diálogo Educacional, v. 19, n. 60, p. 36-55, 2019.

HASHEY, A. I.; STAHL, S. Making online learning accessible for students with disabilities. Teaching Exceptional Children, v. 46, n. 5, p. 70-78, 2014.

KOEHLER, Matthew; MISHRA, Punya. What happens when teachers design educational technology? The development of technological pedagogical content knowledge. Journal of Educational Computing Research, v. 32, n. 2, p. 131-152, 2005.

KOEHLER, Matthew; MISHRA, Punya. Introducing TPCK. In: AACTE. Handbook of Technological Pedagogical Content Knowledge (TPCK) for Educators. Routledge: New York and London, 2008. p. 3-30.

KUOSA, Kirsi. et al. Interactive Visualization in tools to improve learning and teaching online learning environments. International Journal of Distance Education Technologies, v. 14, n. 1, p. 1-21, jan-mar. 2016.

LÉVY, Pierre. A inteligência coletiva: por uma antropologia do ciberespaço. São Paulo: Loyola, 1999. 
MOORE, Michael G.; KEARSLEY, Greg. Educação a distância: sistemas de aprendizagem online. 3. ed. São Paulo: Cengage Learning, 2013.

OLIVEIRA, Édison Trombeta de. EaD e ambientes virtuais de aprendizagem: dimensões Orientadoras para Seleção de Mídias. 2019. 177 p. Tese (Doutorado em Educação) Faculdade de Educação, Universidade de São Paulo, São Paulo, 2019.

OLIVEIRA, Édison Trombeta de; PICONEZ, Stela Conceição Bertholo. Balanço da publicação acadêmica sobre TPACK no Brasil (2008-2015) e suas correlações com os estilos de aprendizagem. In: MIRANDA, L. et al. (Org.). Estilos de aprendizagem e inovações pedagógicas. Santo Tirso: White Books, 2016. p. 105-119.

PLATTNER, Hasso; MEINEL, Christoph; LEIFER, Larry. Design thinking research - Studying Co-Creation in Practice. Springer, 2011.

REYNOLDS, L. et al. Library instruction and information literacy 2015. Reference Services Review, v. 44, n. 4, p. 436-543, 2016.

SANTOS, Boaventura de Sousa. A universidade no século XXI: para uma reforma democrática e emancipatória da Universidade. 3. ed. São Paulo: Cortez, 2010.

SHNAIKAT, Khawla; ALQUDAH, Ayman. High-tech human-touch for online courses: Rules and principles for humanizing your online course. European Scientific Journal, v. 11, n. 16, p. 114-133, jun. 2015.

SHULMAN, Lee. Those who understand: knowledge growth in teaching. Educational Research, v. 15, n. 2, p. 4-14, 1986.

SHULMAN, Lee. Knowledge and teaching: foundations of the new reform. Harvard Educational Review, v. 57, n. 1, p. 1-22, 1987.

SILVERMAN, David. Interpretação de dados qualitativos: métodos para análise de entrevistas, textos e interações. 3. ed. Porto Alegre: ArtMed, 2009.

VYGOTSKY, Lev Semenovitch. A formação social da mente. São Paulo: Martins Fontes, 1984.

Revisão gramatical realizada por:

Nádia Rubio Pirillo.

E-mail: nrpirillo@gmail.com 